Final version published as: Elliott, R. \& Shahar, B. (2017). Emotion-focused therapy for social anxiety (EFT-SA). Person-Centered and Experiential Psychotherapies, advance online publication. DOI: 10.1080/14779757.2017.1330701. (C2017, Routledge. This is an author final version and may not exactly replicate the final version. It is not the copy of record.

\title{
Emotion-Focused Therapy for Social Anxiety (EFT-SA)
}

Robert Elliott \& Ben Shahar

University of Strathclyde \& the Interdisciplinary Center (IDC) Herzliya

Corresponding author: Robert Elliott

Robert Elliott

Counselling Unit

School of Psychological Sciences \& Health

University of Strathclyde

Glasgow G1 1ER

UK

Phone: +44 1415483703

Email: robert.elliott@strath.ac.uk

Ben Shahar

Baruch Ivcher School of Psychology

Interdisciplinary Center (IDC)

P.O. Box 167, Herzliya 46150

ISRAEL

Phone: +972 52340120

Email: bshahar@idc.ac.il

\begin{abstract}
Social Anxiety (SA) is a common, disabling difficulty characterized by persistent fear of other people. After a brief clinical description, we present an Emotion-Focused Therapy (EFT) theory of SA: We describe its developmental origins in experiences of social degradation, which result in primary emotional processes organized around a core sense of shame-ridden defective self. These give rise to secondary reactive anxiety that others will see the person's defectiveness, organized around a coach/critic/ guarding aspect of self that, in the process of trying to keep the person safe from exposure, inadvertently generates the emotional dysregulation characteristic of SA. Following this we present a model and case example for working with SA via an emotional deepening process that begins with accessing secondary reactive anxiety of others in particular situations, then works backwards to accessing and activating primary maladaptive shame so that this emotion scheme can be restructured within a secure, accepting therapy relationship. We conclude with a brief summary of evidence for EFT-SA and some final thoughts about how working with this client population has changed our EFT practice.
\end{abstract}

Key words: Emotion-Focused Therapy, social anxiety, primary and secondary emotions, research 


\section{Emotion-Focused Therapy for Social Anxiety}

Social Anxiety (SA; formerly known as Social Phobia) is a common, debilitating anxiety difficulty characterized by persistent fear of social interactions or situations in which a person might be scrutinized or judged by others (American Psychiatric Association, 2013). People with SA are typically not only terrified of public speaking but of talking or just being seen in a range of social or interpersonal situations (Stravinsky, 2007). It is the third most prevalent psychological difficulty, after depression and substance abuse, affecting up to $12 \%$ of the population during their lifetime (Kessler et al., 2005). SA is often comorbid with other psychiatric diagnoses, and is also associated with impaired ability to form and maintain good interpersonal relationships, leading to loneliness and isolation (Alden \& Taylor, 2004). In addition, there is an increased risk of suicidal ideation and suicide attempts (Cox, Direnfeld, Swinson \& Norton, 1994).

At present, the treatment guidelines (e.g., National Collaborating Centre for Mental Health, 2013; Society of Clinical Psychology, 2016) recommend various forms of CBT as front line evidence-based treatments for SA, such as the Clark and Wells individual model (Clark et al., 2006) and Heimberg's group therapy model (Hope, Heimberg \& Turk, 2010). While these approaches have been shown to be effective (Acarturk, Cuijpers, van Straten, \& de Graaf, 2009; Mayo-Wilson et al., 2014), a substiantial number of clients do not respond well to CBT or remain symptomatic to some degree at the end of therapy (Davidson et al, 2004, Moscovitch, 2009). Our purpose in this article is to present a humanistic-experiential alternative to CBT for SA.

\section{The Nature of Social Anxiety}

As with other anxiety difficulties, social anxiety is a state of mind characterized by persistent fear or worry about perceived danger, in this case, a generalized fear of other people, typically focused on particular types of social situations. Thus, some people with social anxiety are afraid of specific social performance situations, such as public speaking, whereas others fear a broader range of social situations in which they might be negatively judged. This state is often termed generalized social anxiety and is considered a more severe form of this type of difficulty (Mennin et al., 2002). Most people with SA not only experience immediate fears of others but also experience significant distress as they anticipate interactions with other people and later ruminate over them.

Although humanistic-experiential psychotherapists going back to Rogers (1957) have generally distrusted psychiatric diagnosis as conceptually flawed, unnecessarily biological, and politically oppressive, the diagnostic literature (eg, American Psychiatric Association, 2013) does contain useful descriptive information about the conditions under which people are likely to experience their social anxiety as problematic:

- When the anxiety reaches a level that the person experiences as unwanted or unreasonable;

- When the anxiety is inflexibly consistent over time and situations of a particular type;

- When the person either endures feared situations with intense distress or emotional pain, or else avoids them altogether; and

- When the anxiety interferes significantly with the person's functioning or wellbeing.

Like other psychological difficulties, social anxiety exists along a spectrum of severity. Mild to moderate fear or anxiety about particular interpersonal situations, especially involving public performance such as public speaking, interviewing, or dating, is quite common, perhaps even normative, to the point where it can be regarded as a normal personality variation ("shyness," "introversion"). At the other end of the continuum, in our experience most clients who present for psychotherapy for social anxiety are suffering from 
severe levels of fear/anxiety about a range of social situations (e.g., the generalized "type"). Severe SA is highly disabling and essentially ruins the person's life by undermining key sources of personal meaning, that is, life projects such as having friendships, finding and maintaining a close, loving relationship, developing a meaningful career, having children, and so on.

Finally, from an Emotion-Focused Therapy (EFT) point of view, it is important to note that an important feature of experience of social anxiety is experiential and behavioral avoidance. At the same time, people with social anxiety seem to have normal or even greater than average needs for social contact and support, and generally feel quite lonely. This means that they become desperately unhappy with their social avoidance, finding it constricting or even imprisoning, which leads to a sense of stuckness and misery. This stuckness frequently takes the form of depression or substance misuse, both of which are frequently comorbid with SA (Stravinsky, 2007).

\section{An EFT Theory of Social Anxiety}

In EFT terms, Social Anxiety involves a set of maladaptive emotion schemes developed as a result of a person being chronically and traumatically shamed or bullied, usually during the developmental periods of childhood or adolescence. These experiences lead to the development of primary and secondary emotion processes in which interpersonal interactions come to be perceived as dangerous situations in which the person will be revealed as socially defective, thus cuing first shame (a primary maladaptive emotion) and then anxiety about this shame (a secondary reactive emotion), further complicated by patterns of emotion dysregulation (both under- and over-regulation). The complexity and multiplicity of the different emotion processes helps to explain why full-blown social anxiety is so debilitating and so challenging to treat. In Figure 1 we summarize our current understanding of the most common proceses involved in severe social anxiety. These can be divided into sources, primary processes, and secondary processes.

Sources. We propose a social degradation model of the origins of social anxiety (cf. Garfinkel, 1956). During childhood or adolescence, the person (who may or may not have been born with an introverted or shy temperament) experiences a period of social or interpersonal mistreatment. This can take the form of some sort of repeated public humiliation in the form of bullying, or it can involve various forms of interpersonal trauma, that is, physical, sexual or emotional abuse (Kuo, Goldin, Werner, Heimberg \& Gross, 2011). This degradation takes place in the absence of interpersonal support from caregivers, including love, validation, protection and so on, which amplifies the effects of the degradation. This combination of social degradation and lack of support results in traumatic emotional pain, in the form of shame, fear and/or sadness. In the original situation, shame is an immediate primary adaptive emotional response to the degradation, as the person to some extent accepts their portrayal by others as social pariah who deserves to be banished from the company of others.

Primary Emotional Processes. The enduring results of this social degradation process are several, and include first of all a deep, generalized sense of shame. One part of the person might protest angrily against the way they have been mistreated and about their ruined selfidentity, but at another, deeper level, they accept that they are radically and irrevocably defective. Over time, this comes to be symbolized as a shame-ridden defective self, which is experienced as the deepest truth about who they are. Many people with SA are quite successful but feel like impostors, as if they have been able to fool everyone into believing that they have good qualities. They think that only they know the ultimate truth - that they are deeply flawed and live in fearful anticipation that this truth is inevitably going to be "discovered." Each person with social anxiety symbolizes his or her defect in their own 
idiosyncratic way: "stupid," "rubbish," "spacey," "not nice to look at," "unfit for human company," and perhaps most commonly, "having nothing to contribute" - to conversation, to a relationship, or to other people generally.

Along with this, there is a complementary self-organization, in the form of a harsh internal critic, which continually reinforces the sense of defectiveness. This angry, selfjudging aspect is an internalization of the bullies or abusive others who have mistreated the person in the past. In fact, it is this internal voice that repeatedly recites the symbolized defect ("You are awkward and socially inept"; "You're so inarticulate you can't put a coherent sentence together"). Thus, the previous degradation by others now continues as self-degradation and self-shaming, and the person returns again and again to memories of the previous mistreatment, which serve as further evidence in support of self-defectiveness. At the same time the emotional pain of the mistreatment becomes congealed around defectiveness and shame, and the person loses touch with the broader aspects of that pain, such as fear/fragility and isolation/sadness. The result is a one-dimensional experience of self as socially defective.

Secondary Emotional Processes. The shame-ridden defective self-organization leads to a set of secondary emotional processes, which together constitute the clinical presentation of social anxiety, understood in EFT terms as a set of configurations or aspects of self.

First, in response to their chronic maladaptive feelings of shame about being deeply defective, the person develops a self-organization that experiences secondary reactive fear or anxiety that others will see their defectiveness and shame them again. They focus on their fear of other people rather than the more painful shame, and they thus repeatedly see certain types of social situations as dangerous because of the risk of being exposed as socially defective.

Second, in order to cope with chronic feelings of shame, the person develops a hypervigilant coach/critic/guard (CCG) aspect of self, whose role is to continually look out and warn the person about social dangers in order to prevent further degradation. This part of the self is organized around an emotion scheme of fear/distrust, and powerfully motivates the person to engage in various activities to try to keep themselves safe: Most obviously, when in an immediate social situation, such as an informal social gathering or if they have to speak up in a more structured situation such as a class or meeting, people with social anxiety actively scan for signs of impending negative judgement, especially facial expressions like frowns, boredom or contempt. In addition, prior to entering situations, they try to anticipate and prepare possible threats, often mentally composing scripts of what they will say because they are convinced that if they would act spontanously or authentically they will be ridiculed or rejected. Furthermore, after a social encounter they typically replay social interactions over and over to analyze and critique their performance. All of these activities are intended to help the person deal more effectively with social situations; however, their actual effect is to generate more and more fear or anxiety of others, which thus reinforces the person's conscious sense of vulnerability and implicit feeling of shameful defectiveness.

By enhancing and prolonging the person's social anxiety, the hypervigilance of the coach/critic/guard aspect leads to a chronic state of moderate anxiety, vulnerable to periodic overwhelming states of emotion dysregulation ("anxiety attacks"). These underregulated states in turn motivate the person to overregulate their distress through behavioural or experiential avoidance, as the person either flees the situation or shuts themselves down emotionally. In EFT terms, this is a self-interruption, but can be extreme enough at times for the person to enter a quasi-dissociated state in which they experience mental confusion or fuzziness. Finally, these dysregulated states are taken as proof of the person's sense of defectiveness and associated shame. 


\section{Working with Social Anxiety in EFT}

As we see it, the key change process in EFT-SA is an emotional deepening process that begins with accessing and activating secondary reactive fear of others in particular situations, then works backwards to primary maladaptive shame and self-contempt so that these can be restructured within a secure, accepting therapy relationship. Clients are helped to access their sense that they are defective, worthless, inferior, or "damaged goods", then to deepen it to their core pain (eg., deep brokenness or isolation), so that both can be transformed by experiencing and expressing adaptive emotions, such as selfsoothing/compassion, assertive/protective anger, and connecting sadness (Greenberg, 2010; Shahar, 2014). These adaptive emotions strengthen socially anxious individuals and help them to connect with important needs that have been unmet in their lives, thus encouraging them to reestablish or strengthen relationships and fulfill authentic life goals and values. In working with clients with moderate to severe social anxiety we have found a common change process (see Table 1). In elaborating this process, we will illustrate the successive phases of therapy with the case of Daniel (a pseudonym), a 28 year-old man studying abroad in Israel (taken from Shahar, Bar-Kalifa, \& Alon, in press). Originally from Brazil where his unstable mother raised him alone with the help of her extended family, Daniel was eight years old when his mother moved him against his will to be with her new husband in Europe.

\section{Phase I: Making contact and beginning to explore the social anxiety}

Building a genuinely caring and empathic therapeutic relationship. Several things

happen in the intial phase of EFT-SA: First, a secure emotional bond of feeling safe and understood needs to be developed with the client. This can be challenging because clients with SA are generally interpersonally vigilant. In fact, for clients whose social anxiety centers on unstructured social situations, alliance formation often turns out to be a key part of the work, and may require therapists to be more active and to provide more information and structure than they are used to offering. To do this, therapists use a variety of validating empathic responses that reflect their genuine warmth and care for the client. Therapists allow themselves to taste the client's suffering and vulnerability, and to be touched by them.

For example, in the first session with Daniel, he talked about his first night at his new house after they moved to Europe. He could not fall asleep and called his mother, but his new stepfather said, "8-year-olds should fall asleep on their own," and forced his mother to leave Daniel alone, which left him feeling terrified. His therapist responded:

Therapist: Yes, just being there alone in the room, just 8 years old, in a new country, new house, new family, away from everything that's safe and familiar, feeling so alone and terrified.

For socially anxious clients, who usually feel prone to judgment by others, a therapeutic relationship that is based on validation can be highly soothing, affect-regulating and begins to provide a corrective emotional experience.

Exploring and symbolizing the experience of social anxiety. Every client's experience of social anxiety is different, so it is useful, even in the first session, to use empathic exploratory responses in order to help the client elaborate the components of their unique SA emotion schemes:

- How the SA feels in their body (bodily-expressive emotion scheme elements);

- What situations it refers to and what its triggers are (situation/perceptual elements);

- The meanings the client attaches to their SA, what they tell themselves about it, and how they symbolize their social defects (symbolic/conceptual elements);

- How they cope with their SA and what it tells them to do (action tendencies).

- The overall painful felt quality of the SA (emotional elements). 
For example, Daniel experienced his SA in his body as tense and sweaty; his SA was triggered in work and school situations; he symbolized it in terms of him being "stupid" and "lazy"; and it drove him to strive for perfection and avoid situations where he might be judged and shamed. Overall, it had an emotional quality of pervading fear and painful stuckness.

Beginning to construct a social anxiety life narrative. A third kind of initial phase work involves therapist and client starting the process of building a narrative of where the SA fits into the person's life, including the story of how it originated or developed over time, and the life projects that are currently being compromised by it. Through this early narrative work, the therapist also hears the major task markers presented by the client and begins to develop a collaborative case formulation with the client (Goldman \& Greenberg, 2014).

As mentioned earlier, Daniel was originally from Brazil and had been raised primarily by his mother until age 8, when she married another man and moved them to Europe, which Daniel experienced as a traumatic loss of his extended family and protective natural environment. Daniel described his mother as emotionally unstable and paranoid, with frequent anger outbursts, and even psychotic symptoms. As he grew up, Daniel experienced various degrading events, but the one that he recalled as most painful was being forced to move from an international elementary school to a religious Jewish school. Having been popular in the international school, he now felt different, inferior, and excluded in the religious school, and his attempts to convince his mother to let him go back to the international school failed. When he began therapy, Daniel was in a serious romantic relationship but suffered from severe levels of social anxiety symptoms.

Beginning exploration of alternative emotion schemes. Empathic exploration and narrative construction also helped Daniel bring to awareness another part of the self that was sad and lonely because he had experienced various losses as a result of the ongoing emotional and behavioral avoidance. In SA, this part of the self often misses having intimate relationships and mourns the loss of the ability to fully participate and to be fully present in social situations. It is important to bring this part to awareness in Phase I because it serves as an antidote to the dominant, socially anxious Coach/Critic/Guard (CCG) aspect during later split work.

\section{Phase II: Initial Work with Presenting Secondary Anxiety Processes}

From Phase II forward, the change process in EFT-SA involves a step-by-step deconstruction of the client's social anxiety, working backwards through the etiological processes depicted in Figure 1.

Combined Systematic Unfolding and Two Chair Work for anxiety episodes. The diagnostic criteria for social anxiety (American Psychiatric Association, 2013) require that the person sees their fear of others as unreasonable or excessive, which suggests that social anxiety episodes can be treated as Problematic Reaction Points (PRPs; Rice \& Saperia, 1984), that is, puzzling personal reactions to particular situations, markers for the Systematic Evocative Unfolding task in which the therapist asks the client to identify a particular time in which the puzzling reaction happened to them. Thus, client and therapist can enter two-chair work by unfolding a particular episode in which the client was afraid of others, then enact it using chairs. The Unfolding then proceeds as an enactment rather than in a narrative and thus can be seen as both Unfolding and Two Chair work. It is also possible to first move the client into chair work and then have them pick a particular SA episode.

Reports of SA episodes are also anxiety split markers, that is, conflict splits in which one part of the person frightens them in a misguided attempt to keep them safe from social dangers. This part, which we refer to as the Coach/Critic/Guard (CCG), guards the person by coaching them about how to avoid social dangers (by anticipating and rehearsing these), in 
the process taking on the critic function of continually reminding the person of their social defects, for example, "You'd better think about what you're going to say [at the party/at the pub/in class]; otherwise people will see that [you have nothing to contribute/can't speak properly/look stupid]. Maybe you'd be better off staying at home!". The result is fear and anxiety in a vulnerable experiencer part of the person. By the third session this joint $\mathrm{PRP} /$ anxiety split marker is present, and the emotional bond between the therapist and the client is strong enough, to begin deeper emotional processing work. Thus, the therapist typically begins this work by asking the client to identify and unfold a specific example of a social situation in which they were afraid. This unfolding, whether brief or more extended, then leads into work on the anxiety split, with the therapist first offering a brief rationale, then inviting the client to enact the conversation that occurred between the CCG and the experiencer in the situation.

For example, in the third session, Daniel first described a job situation in which he was anxious because he felt judged by his boss; then, the therapist proposed a two-chair dialogue task:

Therapist: So it seems like one part of you stresses you out in these situations, calling you stupid and lazy, telling you that your boss thinks you can't spell right, whereas another part is left feeling anxious and tense... it's in the body right? Feeling sweaty I think you mentioned. Is that right?

Daniel: Yes (nodding his head). I feel like I can't talk because it might come off as... as stupid or something.

Therapist: Right, it sounds like it's so hard to function with this voice in your head that keeps warning and frightening you that things will go wrong, that others will look down on you.

Daniel: (Nods in agreement.)

Therapist: So I suggest we try something to work with that voice, OK? Can you come over here (pointing to an empty chair located in front of the client's chair)? (Daniel agrees and moves to the empty chair which directly faces his usual chair.) See if you can see yourself there (creating contact). How do you stress him out in this situation? Let's actually try to do it.

Daniel: (Looking at the therapist.) I tell him that he's no good.

Therapist: Yeah, so tell him: "You're no good!"

Daniel: (Facing the empty chair.) You're no good, and you must show him that you're competent and make the right impression.

As shown above, after initiating the task and creating contact (e.g., making sure the two sides talk to each other rather than through the therapist), the therapist coaches the CCG to express the anxiety-eliciting catastrophizing messages. In this step it is important to help the CCG be as specific as possible in order to see how anxiety is generated in social situations and even to directly generate it in the session. After the client in the CCG chair expresses the most anxiety-provoking messages, the therapist asks him to switch chairs in order to explore the bodily felt feelings in response to the CCG's attacks.

Therapist: Ok, come over here (pointing to the client's original chair).

Daniel: (Switches to the other chair.)

Therapist: So, look inside... what happens inside as you hear this?

Daniel: $\quad$ Right now I don't feel much, but yesterday when it all happened I know I felt tense.

Therapist: Right, so tell him, tell him how he makes you tense.

Daniel: These things that you tell me, they make me anxious.

Therapist: Like...it's hard to breathe... and...it's like..."I am so scared"?

Daniel: I can't find words in such places so I don't have much to say. 
The therapist helps Daniel explore the bodily-felt tension and anxiety in response to the CCG's messages. The therapist uses a variety of empathic conjectures to help Daniel deepen the process and actually experience the tension in the session.

Emotion regulation work. An important feature of EFT-SA is the need to help clients manage within-session episodes of emotion dysregulation, which commonly occur when they begin working with anxiety splits. These include both under- and over-regulation. As noted earlier, the CCG aspect at times overwhelms the vulnerable self-experiencer, which leads to in-session anxiety or even panic episodes, to which clients respond with experiential and/or behavioral avoidance, including emotionally shutting down, experiencing mild dissociation, or even leaving the session. It is thus important to actively help them regulate overwhelming anxiety or mild dissociation by stopping whatever work is going on to address the dysregulation through empathic affirmation, breathing or mindfulness suggestions (e.g., gently: "Yeah, there is so much anxiety right now, I know, it's so scary... see if you can take a breath. I'm with you."), and through normalization and experiential teaching ("Great! This is a therapeutic opportunity. It's just the emotion centers of your brain flooding the attention centers with stress hormones, partially shutting them down. How did the critic part of you do that?"). Such moments of therapist-client dyadic regulation can be healing because so often these clients have been alone in this process. If mishandled through therapist passivity or lack of strong empathic affirmation these dysregulation processes will undermine the therapy or become relational ruptures. On the other hand, if the therapist is able to actively and sensitively work with client, they can become therapeutic opportunities, in that they help the client experience directly how they generate their social anxiety or shut themselves down.

Clients with SA also frequently become over-regulated, numbing themselves or avoiding feelings so that it is difficult for them to access their experiences. This was the case with Daniel, who did not feel much anxiety in the session. With him, the focus was more often on the anxiety he experienced in specific out-of-session situations. Unfolding and Focusing are both useful tasks in exploring such situations, and help clients heighten the bodily experience of the anxiety (in Daniel's case sweating), as is helping the CCG to describe or enact how it elicits that response. This further intensifies the criticism and clarifies the anxiety generating process:

Daniel: Yeah, and I often start to sweat a little, and I am afraid that others can see that.

Therapist: Ok, come over here.

Daniel: (Moves back to the CCG chair.)

Therapist: How do you make him sweat?

Daniel: (using a contemptuous tone) Look at you, you have nothing to say, so now he thinks you're stupid and will fire you.

By helping clients regulate their anxiety in the session so that they can experience the anxiety split process and develop awareness of how they make themselves anxious, the therapy begins to make space for deeper processes.

\section{Phase III: Deepening: Working with primary shame processes}

Having reached an understanding of how the CCG aspect of the self generates fear of other people, client are ready to begin the process of facing their core sense of defectiveness, which the secondary processes (including the CCG) explored in Phase II had been containing or warding off. Sharing their curiosity with the client, therapists gently help them explore the specific nature of the danger that CCG has been trying desperately to protect against. This leads to an exploration of the primary maladaptive shame emotion scheme that drives the secondary fear of others, and specifically the sense that they are fundamentally defective as human beings. This level of shame brings clients to a deeply vulnerable state, which is very difficult for them to stay with; thus, it requires close tracking and actively communicated 
empathic affirmation to hold clients emotionally. Genuineness, unconditional positive regard and active prizing of clients are essential here, as is continuing to work with their immediate or delayed secondary reactions to primary shame. This work takes courage and active engagement on the part of both clients and therapists, supported by chair work, focusing and emotion regulation efforts.

Once a therapist and client are able to help the client stay with primary shame, the next step becomes exploring the deeper self-critical split by which another part of the client continually shames him or her through harsh self-criticism and self-contempt. In our experience, this is a deeper, harsher part of self that differs from the CCG in the absence of an apparent protective function: regardless of the developmental origins of the SA, this part of the person has come to treat self as defective and broken, "not fit for human company". Thus, therapists help clients to work with their harsh internal critic and its introjected, selfdirected anger and contempt. This helps them experience directly how their sense of defectiveness, like their fear of others, is a product of an internal, self-generated process.

Thus, in his fifth session Daniel described another social situation in which he was anxious, and the therapist again suggested that they work on this using the chairs to look at how his CCG functions, here symbolized as a critical "supervisor". As the CCG expressed the most degrading comments, the shame scheme was activated, even if for a few seconds, in the experiencing-self chair:

Daniel: (Looking down, shoulders slump.)

Therapist: (after a few seconds) So hurt, so painful. It's tough to hear...it's so degrading.

Daniel: Yeah, I just feel inferior, like I'm not worth shit.

Therapist: Yeah, I imagine this is the hardest feeling. Feeling so worthless. Just wanting to hide somewhere (action tendency of shame).

Daniel: $\quad$ Right. I don't want to be here.

Therapist: To disappear somehow.

Usually at this point an adaptive emotion scheme - sadness or anger - begins to emerge spontaneously, so it is important for the therapist to pay attention to nonverbal signs (usually voice quality) of that scheme and to support its emergence. As Daniel experienced shame, he began to feel resentment for "having to be someone else that I'm not" and the therapist supported him in expressing the anger and its associated needs. It is important for therapists to be aware that as clients access shame in a context of a safe and validating relationship, sadness and anger naturally emerge as an antidote for shame; there is generally no need for the therapist to have to pull for them. These primary adaptive emotions led to expressing basic needs that were important to Daniel's well-being, and were likely to promote emotional and behavioral changes. In addition, accessing shame and subsequent adaptive anger led to an important dialogue, in which the protective function of the CCG were expressed (i.e. to prevent humiliation) and the CCG softened into anxiety:

Therapist: (Daniel is in the CCG chair) It's so scary...this possibility, this feeling of being humiliated. Can you tell him about this anxiety?

Daniel: Yeah, I'm afraid of this feeling. I can't let it happen.

Therapist: Right, so this is the anxiety that drives you. Tell him about what you're most afraid of?

Daniel: That people will look down on you and think that you're less than... and they will see this little vulnerable boy.

Therapist: They will see this weak part of you.

Daniel: $\quad$ Yes, the part of you when you were very little. 


\section{Phase IV: Emotional Change: Working with and Repairing the Sources of Social Anxiety}

Sometimes working with the deeper anxiety and self-shaming splits is enough to generate emotional transformation through mobilizing protective anger, connecting sadness or self-compassion. In other instances, the work moves on to the developmental sources of the SA. These are often either obvious or easily accessed at this point, revealing the client's social anxiety as a form of complex trauma (Paivio \& Pascual-Leone, 2010). Thus, client and therapist begin working on unfinished business from unresolved developmentally important relationships, in particular unexpressed feelings and unmet needs.

For Daniel, the sources of the social anxiety involved, first, the fear that others would see him as like his unstable/weak/vulnerable mother, and, second, prior experiences of being rejected and feeling not worthy of love. In particular, he remembered the first night at his new home in Europe when he couldn't fall asleep but was abandoned by his mother and forced to remain alone. Also, being "moved like a doll from place to place" contributed to feeling "like nothing for no one".

Making use of empty chair work, client and therapist follow the emotional deepening process in working with unfinished business, helping the client move from secondary protest and complaint about their mistreatment to their core traumatic pain, or what hurts the most, about the degrading experiences they went through. (Clients can also arrive at their core pain via deeper chair work with the CCG.) Following Timulak (2015), we have found that this core pain most commonly takes one of several forms: First, there can be intense feelings of fragility or exposure, which points to a generalized maladaptive existential fear of shattering or dying. Second, what hurts the most can be a sense of having been fundamentally violated or injured by degrading treatment by others, leaving the person full of shame and self-disgust ("damaged goods"). However, in our experience a third form of core pain is most often present: a deep sense of having been abandoned or categorically rejected by others, as if their defectiveness was so great as to cause the person to be entirely cast out of or shunned by their social unit, leaving them stuck in a deep sense of emptiness, loneliness and disconnection.

Thus, in session 17, Daniel's feelings of shame in the experiencing chair led to episodic memories of being rejected:

Daniel: When I am judged I feel so alone... I feel like again this little boy... When I was a little boy I had no one not even a friend.. not even my mom hugged me that night. It's like you're not worth your mother, you're not worth your grandmother, you're worth being alone there.

Therapist: That's all you're worth... Try and see your mom here and be that little boy.

Daniel: I am so angry at you! Why couldn't you... I was only 8 (sobs)! And you were pushing me to sleep alone and screaming at me. I needed you to be there for me and hug me and tell me things are going to be fine.

Once the client accesses their core pain, the next step is to enter into transformative self-soothing (Goldman \& Fox, 2010; Sutherland, Peräkylä \& Elliott, 2014). In this process, the therapist accepts the core pain and helps the client identify what it needs, which in turn activates an appropriate, primary adaptive emotion in the client. Thus, fragility or exposure needs protection and safety, which points to self-compassion, as if parenting oneself as a frightened child; violation needs to be caringly protected from harm, which activates protective anger, supporting the self in reassigning the fault for past degradation and making better boundaries in current relationships; and abandonment/rejection transforms into connecting sadness, which motivates the person to seek others in the face of their fears. The therapist helps the client to access these adaptive emotions as resources for addressing their core pain: 
Therapist: So can you come over here? And this is Daniel now ok? Can you see this little boy?

Daniel: (Sobs...) Yeah.

Therapist: Can you give him what he needs?

Daniel: $\quad$ Everything is fine...you know when you were so alone, it's not that she judged you, she was confused and she also took a big step.

Therapist: So it's like...it wasn't your fault?

Daniel: Right, it wasn't your fault, it didn't mean that you are worthless.

Therapist: What do you actually feel inside when you look at him and tell him these things? See the 8-year-old...

Daniel: I feel like... I feel sorry for him, I am sad for him.

Therapist: So it's this warm feeling I guess... What do you want to do with this feeling?

Daniel: I want to comfort him... and tell him everything's fine.

Therapist: So tell him. Comfort him. Be his mother that he never had.

Daniel: It's ok... I am here for you. We'll go through this together. I'm here (turning to the therapist). This is what I needed. It's so simple. I just needed her to help me through.

In session 21, this process was further deepened using imaginal restructuring, in which Daniel was guided in imagery to go back to the religious school and provide comfort and soothing and guidance to the little boy who was alone and having a hard time adjusting. These experiences are essential, as they fulfil his previous unmet needs, thus transforming and correcting, or reconsolidating (Lane, Ryan, Nadel, \& Greenberg, 2015) the shame emotion scheme into a self-compassion emotion scheme, resulting in more confidence in social situations.

\section{Phase V: Consolidation and Ending}

These new, emerging emotions form the basis of new, more useful self-organisations, leading to far-reaching changes in emotion schemes for self and others, behavior change and more fulfilling interactions with others. However, addressing the traumatic pain and the primary processes of shame and harsh self-criticism do not automatically lead to change in the secondary processes of social anxiety. Afterall, the CCG anxiety split process has over time become a stable self-organization in its own right, a well-worn path of experience, an old friend. Thus, there needs to be a process of working back out from the primary processes to the secondary ones, a carrying forward. Thus, we have found that it is important to help the client to consolidate the more fundamental changes and to translate these into their current life functioning by confronting and overcoming the entrenched avoidant processes, reclaiming the right to connect with others in a meaningful way, experimenting with being authentically present in social situations. This process of consolidation may last several months, during which time client and therapist may agree to meet less often, gradually tapering the frequency of sessions, as they prepare for and process the end of therapy. This also allows them to deal with any set-backs or emergent situations in the client's life that may reactivate the CCG, providing it opportunities for further softening and transformation into a helpful resource while at the same time being supported and reassured about the importance of maintaining a healthy balance between careful, reflective and spontaneous, assertive aspects of self.

In this stage the therapist and the client go back to two chair dialogue in order to consolidate the change. For example, in session 24, in a dialogue with the CCG, Daniel in the experiencing chair says:

Daniel: I am seeing him in the other chair and I have this sense that I am calmer than him. Like...he's anxious to be more, more, more... and is running 
around... and stressed, but when I am sitting here I feel calm and more confident.

Therapist: So what does he need from you? So this is the scared, stressed, running around Daniel over there. What does he need from you?

Daniel: To hear that it's OK, we are fine now.

Therapist: Yeah, tell him, calm him down.

Daniel: You don't need to run around anymore. You don't need to be anxious anymore, you don't need to run from something that is not there.

\section{Research on EFT for Social Anxiety}

Two group outcome studies EFT-SA have been carried out: Shahar et al. (in press) have recently reported the results of a multiple baseline design with 12 clients who were offered up to 28 sessions and randomized to wait four, eight or 12 weeks between intake and beginning therapy. Of the 11 completers, seven no longer met criteria for SA at the end of treatment; social anxiety scores did not change during baseline, but showed very large and statistically significant improvements during treatment, and remained improved during follow-up. Elliott and colleagues (Elliott, 2013, Elliott, Rodgers \& Stephen, 2014) compared EFT to Person-Centered Therapy (PCT) in a sample of 53 clients with moderate to severe SA who were offered up to 20 sessions. Overall effects of EFT on social anxiety and presenting problems were large and superior to PCT. While not definitive, these two studies provide clear evidence supporting the further development and testing of EFT as a promising evidence-based treatment for social anxiety, with large benefits for clients.

\section{Conclusion}

In this chapter, we have laid out our approach to applying EFT to clients presenting with social anxiety (EFT-AS), a debilitating fear of other people. It is our view that this approach is promising because it provides an alternative to a common but difficult-to-treat psychological difficulty that up until now has been almost exclusively the province of CBT; this is important because in our experience many clients have either had previous unsuccessful courses of CBT for SA or prefer a less directive, more relational approach. In addition, it is our view that EFT-AS can help EFT practitioners extend their practice to a new, challenging and complex client population, helping them to develop additional skills for working effectively with all their clients: First, we can improve how we work with clients who are deeply shame-ridden and display high levels of interpersonal vigilance in sessions, putting us under a microscope. Second, we can learn how better to meet clients who are likely to be phobic of unstructured social situations of which therapy is an exemplar and who therefore demand that we become more process guiding. Third, we can develop a wider, more flexible approach to working with a set of clients who easily become emotionally dysregulated in sessions, or who because of their social anxiety have a kind of interpersonal allergy to chair work. Fourth, we can add compassionate self-soothing to the set of therapeutic tasks we are able to offer clients. Meeting and learning from these challenges over the past ten years has made us both better EFT therapists, and we are grateful to our clients for their trust and courage in bringing these challenges to us.

\section{Author Biographies:}

Robert Elliott, is Professor of Counselling in the Counselling Unit at the University of Strathclyde, Glasgow, Scotland. He is co-author of Facilitating Emotional Change and Learning Emotion-Focused Therapy. He recipient of the distinguished career award of the Society for Psychotherapy Research and of the 2008 Carl Rogers Award of the Division of Humanistic Psychology of the American Psychological Association. 
Ben Shahar, is a clinical psychologist, the co-founder of the Israeli Institute for EmotionFocused Therapy and an adjunct faculty member at the Baruch Ivcher School of Psychology at the Interdisciplinary Center (IDC) in Herzliya, Israel. He is an EFT supervisor and trainer and has published several articles on EFT for social anxiety and self-criticism.

\section{References}

Acarturk, C., Cuijpers, P., van Straten, A., \& de Graaf, R. (2009). Psychological treatment of social anxiety disorder: A meta-analysis. Psychological Medicine, 39(2), 241-254. doi: $10.1017 / \mathrm{S} 0033291708003590$

Alden, L.E., \& Taylor, C.T. (2004). Interpersonal processes in social phobia. Clinical Psychology Review, 7, 857-882.

American Psychiatric Association. (2013). Diagnostic and statistical manual of mental disorders (5th ed.). Washington, DC: Author.

Clark, D., Ehlers, A., Hackmann, A., McManus, F., Fennell, M., Grey, N., Waddington, L., \& Wild, J. (2006). Cognitive Therapy Versus Exposure and Applied Relaxation in Social Phobia: A Randomized Controlled Trial. Journal of Consulting \& Clinical Psychology, 74, 568-578.

Cox, B.J., Direnfeld, D.M., Swinson, R.P., \& Norton, G.R. (1994). Suicidal ideation and suicide attempts in panic disorder and social phobia. American Journal of Psychiatry, $151,882-887$.

Davidson, J.R., Foa, E.B., Huppert, J.D., Keefe, F.J., Franklin, M.E., Compton, J.S., Zhao, N.,Connor, K., Lynch, T.R., \& Kishore, G. (2004). Fluoxetine, comprehensive cognitive behavioural therapy, and placebo in generalized social phobia. Archives of General Psychiatry, 61, 1005-1013.

Elliott, R. (2013). Person-Centered-Experiential Psychotherapy for Anxiety Difficulties: Theory, Research and Practice. Person-Centered and Experiential Psychotherapies, 12, 14-30. DOI:10.1080/14779757.2013.767750

Elliott, R., Rodgers, B., \& Stephen, S. (June, 2014). The Outcomes of Person-Centred and Emotion-Focused Therapy for Social Anxiety: An Update. Paper presented at conference of the Society for Psychotherapy Research, Copenhagen, Denmark.

Garfinkel, H. (1956). Conditions for Successful Degradation Ceremonies. American Journal of Sociology, 61, 420-424.

Goldman, R., \& Fox, A. (May, 2010). Self-soothing in emotion-focused therapy: Findings from a task analysis. Paper presented at conference of Society for the Exploration of Psychotherapy Integration, Florence, Italy.

Goldman \& Greenberg (2014). Case formulation in emotion-focused therapy. Washington, DC: APA.

Hope, D.A., Heimberg, R.G., \& Turk, C.L. (2010) Managing social anxiety: A cognitivebehavioral therapy approach (2nd Ed). Oxford, UK: Oxford University Press.

Kessler, R. C., Berglund, P., Demler, O., Jin, R., Merikangas, K. R., \& Walters, E. E. (2005). Lifetime prevalence and age-of-onset distributions of DSM-IV disorders in the national comorbidity survey replication. Archives of General Psychiatry, 62(6), 593-602. doi:10.1001/archpsyc.62.6.593

Kuo, J. R., Goldin, P. R., Werner, K., Heimberg, R. G., \& Gross, J. J. (2011). Childhood trauma and current psychological functioning in adults with social anxiety disorder. Journal of Anxiety Disorders, 25(4), 467-473. doi:10.1016/j.janxdis.2010.11.011

Lane, R.D., Ryan, L, Nadel, L, \& Greenberg, L. (2015). Memory reconsolidation, emotional arousal, and the process of change in psychotherapy: New insights from brain science. Behavioral \& Brain Sciences, 38, el (19 pages). doi: 10.1017/S0140525X14000041. 
Mayo-Wilson, E., Dias, S., Mavranezouli, I., Kew, K., Clark, D. M., Ades, A. E., \& Pilling, S. (2014). Psychological and pharmacological interventions for social anxiety disorder in adults: A systematic review and network meta-analysis. The Lancet Psychiatry, 1(5), 368-376. doi:http://dx.doi.org/10.1016/S2215-0366(14)70329-3

Mennin, D.S., Fresco, D.M., Heimberg, R.G., Schneier, F.R., Davies, S.O., \& Liebowitz, M.R. (2002). Screening for social anxiety disorder in the clinical setting: Using the Liebowitz Social Anxiety Scale. Journal of Anxiety Disorders, 16, 661-673.

Moscovitch, D. A. (2009). What is the core fear in social phobia? A new model to facilitate individualized case conceptualization and treatment. Cognitive and Behavioral Practice, 16(2), 123-134. doi:10.1016/j.cbpra.2008.04.002

National Collaborating Centre for Mental Health (2013). Social anxiety disorder: Recognition, assessment and treatment [National Clinical Guideline Number 159]. London: National Institute for Clinical Excellence.

Paivio, S.C., \& Pascual-Leone, A. (2010). Emotion-focused Therapy for Complex Trauma. Washington, DC: APA.

Rice, L. N., \& Saperia, E. P. (1984). Task analysis and the resolution of problematic reactions. In L. N. Rice \& L. S. Greenberg (Eds.), Patterns of change (pp. 29-66). New York: Guilford.

Rogers, C.R. (1957). The necessary and sufficient conditions of therapeutic personality change. Journal of Consulting Psychology, 21, 95-103.

Society of Clinical Psychology. (2016, April 27). Research-supported psychological treatments. Retrieved from: http://www.div12.org/psychological-treatments/

Shahar, B. (2014). Emotion-focused therapy for the treatment of social anxiety: An overview of the model and a case description. Clinical Psychology \& Psychotherapy, 21, 536547.

Shahar, B. Bar-Kalifa, E., \& Alon, E. (in press). Emotion-Focused Therapy for Social Anxiety Disorder: Results from a Multiple-Baseline Study. Journal of Consulting and Clinical Psychology.

Stravynski, A. (2007). Fearing Others: The nature and treatment of social phobia. Cambridge, UK: Cambridge University Press.

Sutherland, O., Peräkylä, A., \& Elliott, R. (2014). Conversation Analysis of the Two-Chair Self-Soothing Task in Emotion-Focused Therapy. Psychotherapy Research. Advance online publication. doi: 10.1080/10503307.2014.885146

Timulak, L. (2015). Transforming emotional pain in psychotherapy: An emotion-focused approach. Hove, East Sussex: Routledge. 
Phase I: Making contact and beginning to explore social anxiety

(a) Alliance Formation

(b) Empathic exploration/focusing for accessing, deepening, and symbolizing experience of social anxiety (emotion scheme work)

(c) Narrative work for developing a coherent account of the social anxiety in the person's life

(d) Beginning to explore alternative emotion schemes

Phase II: Initial work with presenting secondary anxiety processes:

(a) Systematic Unfolding of social anxiety episodes, leading into two chair work on anxiety splits (secondary reactive anxiety/fear)

(b) Emotion regulation work

Phase III: Deepening: Working with primary shame processes:

- Two chair work (with Focusing) on deeper self-critical split: defective self vs. harsh critic (primary maladaptive shame/fear)

Phase IV: Emotional Change: Working with and repairing the sources of social anxiety

(a) Empty Chair work with developmentally significant degradation experiences, leads into core pain, unmet needs, leads into:

(b) Compassionate self-soothing (primary adaptive emotions: connecting sadness, protective anger, exploratory curiosity) (Repeated as needed within and across sessions)

Phase V: Consolidation and ending

- Tapering off frequency of therapy; helping client carry forward changes in their life; preparing for and processing end of therapy 
Figure 1. EFT Model of Social Anxiety

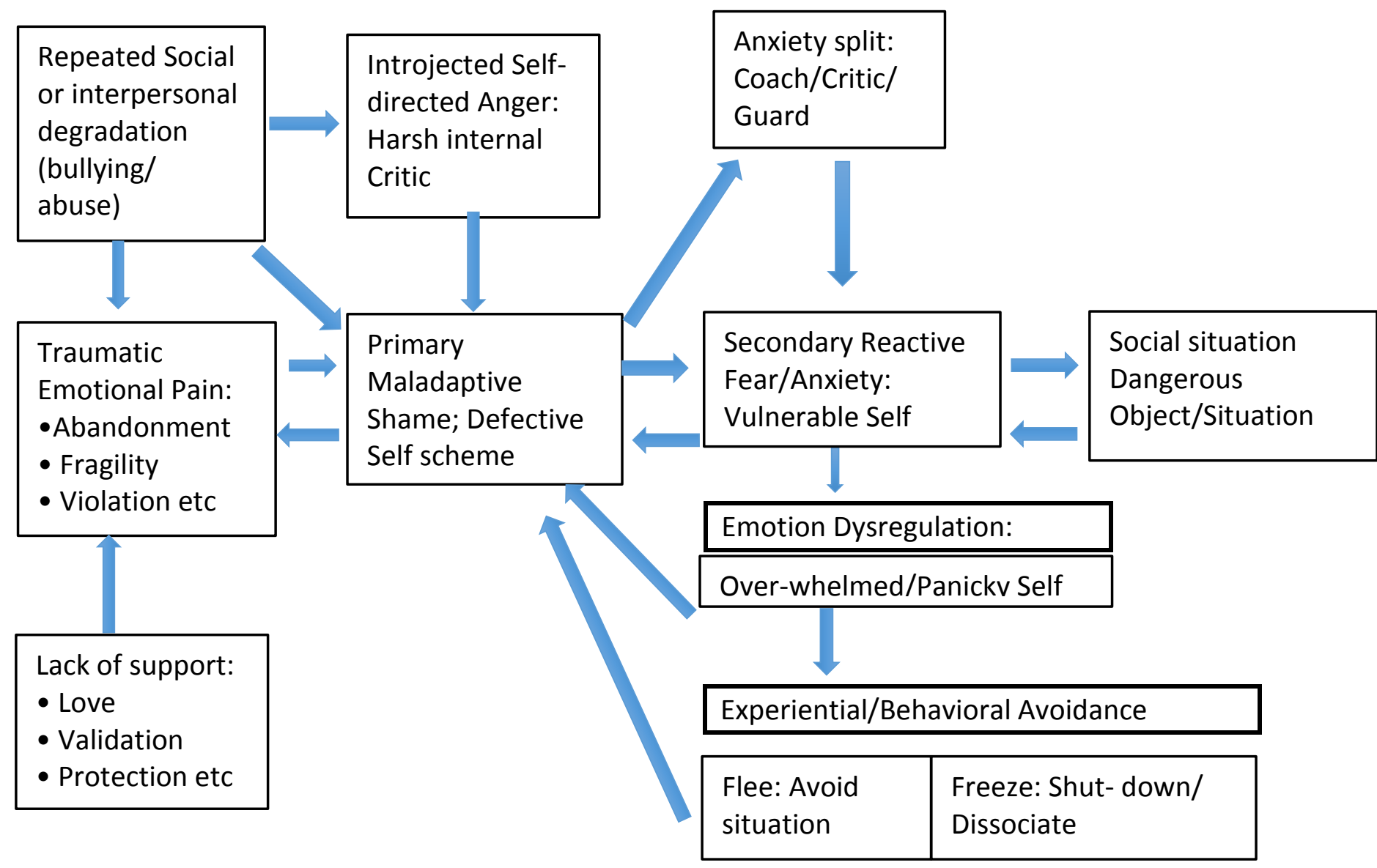

Sources

Primary Emotional Processes

Secondary Emotional Processes

(C) Robert Elliott 2016 